\title{
Human saliva as a source of anti-malarial antibodies to examine population exposure to Plasmodium falciparum
}

\author{
Patricia Tabernero Estévez ${ }^{1}$, Judith Satoguina ${ }^{2,3}$, Davis C Nwakanma ${ }^{2}$, Sheila West ${ }^{4}$, David J Conway ${ }^{1,2}$ and \\ Chris J Drakeley ${ }^{1 *}$
}

\begin{abstract}
Background: Antibody responses to malaria antigens reflect exposure to parasites, and seroprevalence correlates with malaria transmission intensity. Antibodies are routinely measured in sera or on dried blood spots but a non-invasive method would provide extra utility in sampling general populations. Saliva is already in use in the detection of plasma-derived IgM and IgG to viral infections. In this study, antibodies to Plasmodium falciparum merozoite antigens were compared between blood and saliva samples from the same individuals in unlinked surveys conducted in Tanzania and The Gambia.
\end{abstract}

Methods: In Tanzania, 53 individuals provided paired fingerprick blood and saliva sample using two commercially available sampling devices. In the Gambia, archived plasma and saliva samples collected from 200 children in the Farafenni area in a cross-sectional survey were analyzed.

IgG antibodies against $P$. falciparum antigens, Merozoite Surface Protein-1 (MSP-1 ${ }_{19}$ ) and Apical membrane Antigen (AMA-1) were measured by ELISA in paired saliva and blood samples from both sites. Antibody levels were compared as continuous optical density (OD) values and by sero-positivity.

Results: Significant correlations between saliva and plasma antibody levels were seen in Tanzania for both antigens, AMA-1 $\left(r^{2}\right.$ range 0.93 to $\left.0.89, p<0.001\right)$ and MSP-1 $19\left(r^{2}\right.$ range 0.93 to $\left.0.75, p<0.001\right)$, with a weaker correlation for results from The Gambia ( $r^{2}$ range 0.64 to $0.63, p<0.01$ ). When assessed as seropositivity and compared with plasma, sensitivity and specificity were good with saliva antibody levels to both AMA-1 and MSP-1 19 (sensitivity range 64-77\% and specificity range $91-100 \% \& 47-67 \%$ and $90-97 \%$ respectively) over the different sample sets.

Conclusions: These data demonstrate anti-malarial antibodies can be detected in saliva and correlate strongly with levels in plasma. This non-invasive relatively simple collection method will be potentially useful for general population surveys, and particularly in migratory populations or those with infrequent contact with health services or opposed to blood withdrawal. Further studies will be needed to optimize collection methods, standardize volumes and content and develop controls.

\section{Background}

The strengthening of control efforts has successfully reduced malaria burden in many countries and reawakened discussions of malaria elimination [1]. Whilst conjecture remains about whether elimination can be achieved there is a need to more accurately define

\footnotetext{
* Correspondence: chris.drakeley@lshtm.ac.uk

${ }^{1}$ Faculty of Infectious \& Tropical Diseases, London School of Hygiene and Tropical Medicine, London, UK

Full list of author information is available at the end of the article
}

malaria exposure at the low levels of transmission, which will inevitably be encountered if control measures succeed [2-4]. More accurate estimates of exposure and transmission intensity will allow the evaluation of the impact of control activities and deployment of future control methods [5].

Parasite rate (PR) and the entomological inoculation rate (EIR) are the measures widely used to estimate the transmission intensity for malaria, but these have poor precision at low transmission levels [6]. It has previously

\section{Biomed Central}


been shown that anti-malarial antibodies as age specific seroconversion rates are an effective tool to assess malaria endemicity and burden of the disease [5,7-9]. Antibodies can persist for months or years after infection and, therefore, may have particular utility as a proxy measure of malaria transmission in low transmission settings [6].

Samples for both PR and serological estimations are typically collected as blood by finger prick. However, drawing blood involves risk of accidental infections (albeit minor) in resource-poor environments and presents challenges in communities with blood taboos $[10,11]$. One alternative is oral fluid which is a mixture of IgA-rich saliva and IgG-rich crevicular fluid (a transudate of serum expressed at the crevice between teeth and gums) and is already a substitute of serum samples in the diagnosis of several pathogens, such as HIV $[12,13]$. Commercial saliva-based kits for HIV and illicit drugs are already available for the detection of human antibodies for population-based studies [12,14].

Plasmodium DNA has been successfully detected in saliva samples [15-17] and the additional detection of antibodies would be a further considerable benefit in developing rapid, safe and affordable approach to determine exposure to and infection with Plasmodium falciparum. The objective of this study was to evaluate oral fluid as an alternative to blood collection for the detection of anti-malarial antibodies. The study reports results from a prospectively designed collection of paired plasma and saliva samples in Tanzania and retrospective analysis with the same ELISA methodology of archived plasma and saliva samples from a previously conducted study in The Gambia [15].

\section{Methods}

\section{Study sites and conduct: Tanzania}

The study was conducted in July 2009 in rural-central Tanzania in the villages of Ihanda and Ndurugumi, in Dodoma Region. In this area, malaria is hypoendemic with transmission occurring primarily during and immediately after the rainy season, from January to March. This survey was conducted over a two week period July 2009 and nested within a larger study investigating the impact of azithromycin for Trachoma treatment on malariometric indices. The eligible subjects for the study were parents with a child under five years old and these were included on a first come first serve basis during the survey period. The aim was to compare antibody responses to malaria antigens in saliva collected with two commercially available saliva collection devices with antibody responses in plasma from the same individuals. None of the participants had clinical symptoms of malaria at the time of the survey. This project received ethical approval from the Ethical Committees of the
National Institute for Medical Research in Tanzania and the London School of Hygiene and Tropical Medicine. Individual informed consent was obtained in Swahili from the enrolled individuals.

\section{Study site and conduct: The Gambia}

In The Gambia, samples were collected in a cross sectional malaria survey in August 2008. The primary aim of the study was to evaluate the sensitivity of parasite DNA detection in saliva for diagnosing malaria. Salivary anti-malarial antibodies were measured in a second analysis. Following informed consent from either the parent or guardian of eligible study participants, a baseline malaria screening of children aged 1 to 15 years was conducted in seven villages around the Farafenni area. In the Gambia malaria is seasonal, occurring mainly during the rainy season from July to November with a peak in September. The study was jointly reviewed and approved by the Gambian Government-Medical Research Council Laboratories Ethics Committee and the Programme for Appropriate Technology in Health (PATH) Research Ethics Committee (REC) USA.

\section{Sample collection and processing: Tanzania}

On completion and signing of the informed consent, saliva was taken from the parent and then the parent obtained the sample from the child. Oral fluid was collected from each participant using two different commercially available devices, Oracol (Malvern Medical Developments Limited, Worcester, U.K.) and OraSure-Intercept (OraSure Technologies, Inc. Bethlehem, PA, US). These devices have previously been used in the surveillance of viral and bacterial diseases $[10,18-20]$ and were selected in order to better understand the efficiency of anti-malarial antibody elution from human saliva. Oracol was used as previously described $[19,21,22]$. Timers were used to be consistent with the time when collecting the saliva samples in each individual with a maximum of two minutes per swab allowed. Samples were initially stored in a cool box prior to longer-term storage at -20 degrees. For both devices, the specimens were centrifuged at $1000 \mathrm{~g} / \mathrm{min}$ for $5 \mathrm{~min}$ $[18,19,21]$, swabs were discarded and the extracted saliva was pipetted into a $1.5 \mathrm{ml}$ tube and stored at $+4^{\circ} \mathrm{C}$ until testing.

The blood samples were collected by finger prick on to Whatman $3 \mathrm{M}$ filter paper, dried with silica gel and stored at $+4^{\circ} \mathrm{C}$ until testing. The reconstitution of dried blood spots was conducted as previously described [8]. Briefly, a $3.5 \mathrm{~mm}$ diameter circle was punched out from a blood spot and reconstituted by adding $300 \mu \mathrm{l}$ of the reconstitution buffer made from PBS/Tween wash solution and $0.1 \%$ Azide after overnight agitation. 


\section{Sample collection and processing: The Gambia}

Approximately $1 \mathrm{ml}$ of saliva was collected directly into sterile $50 \mathrm{ml}$ falcon tube by spitting and concurrently, $250 \mu \mathrm{l}$ of finger prick blood was collected into EDTA microtainer tube from each study participant. Samples were temporarily kept in a cold box in the field and processed for storage at the laboratory within $2 \mathrm{H}$ of collection. The plasma fraction was separated from whole blood by centrifugation at 2,500 rpm while the saliva samples did not undergo further processing. All samples were stored at $-20^{\circ} \mathrm{C}$ until serological assays were carried out.

\section{Serological assays}

A quantitative enzyme-linked immunosorbent assay (ELISA) was used to analyse oral fluid and blood samples to detect IgG antibodies to recombinant blood stage $P$. falciparum malaria antigens AMA-1(3D7) and $\mathrm{MSP}_{19}$ (Wellcome) [23] and conducted as previously described $[6,8]$. Briefly, Immulon-4 plates (Nunc) were coated overnight with $50 \mu \mathrm{l}$ of $0.5 \mu \mathrm{g} / \mathrm{ml}$ the antigen. After blocking $50 \mu \mathrm{l}$ of each of the samples and standards (a pool of positive sera from The Gambia) were added to duplicate wells; filter paper eluate and plasma were tested at a final dilution of 1:1,000 for MSP- $1_{19}$ and 1:2,000 for AMA-1. Saliva was used undiluted. The plates were incubated over night at $4 \mathrm{C}$ after which rabbit antihuman IgG-antibody conjugated to horse-radish peroxidase (Dako) was added at a dilution of 1:5,000. Antibody responses were detected as optical densities (OD) after development with o-phenylenediamine (OPD) and reading at a wavelength of $490 \mathrm{~nm}$ on a spectrophotometer. In the absence of known positive and negative saliva samples serial dilutions of a pool of positive sera control was included on each ELISA plate together with a nonimmune control pool as negative control.

\section{Statistical analysis}

ELISA OD were converted to antibody titres expressed in Arbitrary Units $(\mathrm{AU} / \mathrm{ml})$ using the standard curve from a pool of hyperendemic sera. Paired t-tests of the continuous data were conducted and correlation coefficients calculated. A mixture model was used to define an arbitrary cut-off for positivity for each sample collection method [8]. Briefly, the distribution of normalized OD values was fitted as the sum of two Gaussian distributions (a narrow distribution of sero-negatives and a broader distribution of sero-positives) using maximum likelihood methods. The mean OD of the Gaussian corresponding to the sero-negative population plus three standard deviations was used as the cut-off for seropositivity. A separate cut off was generated for each antigen and each sample type (plasma \& saliva). Sensitivity analysis was conducted in Stata11 (Statacorp, Texas).

\section{Results}

Matched filter paper or plasma samples and saliva were available from 53 Tanzanian participants and 200 Gambian participants. Antibody titre results from saliva compared well with those from plasma in both settings and for all antigens. In Tanzania AMA-1 titres showed highly significant correlation between the two fluids and with both oral fluid devices $\left(r^{2}\right.$ Oracol-fingerprick $=0.89$, $\mathrm{r}^{2}$ Orasure-Fingerprick $=0.93$, both $\mathrm{p}<0.001$, figure $1 \mathrm{a}$ $\& 1 b$, Table 1). Similar results were seen for antibodies against MSP- $1_{19}\left(\mathrm{r}^{2}\right.$ Oracol-fingerprick $=0.75, \mathrm{r}^{2}$ Orasure-Fingerprick $=0.94$, both $\mathrm{p}<0.001$, figure $1 \mathrm{c} \& 1 \mathrm{~d}$, Table 1). Data from The Gambia also showed significant correlations for all antigens tested though overall correlation coefficients were lower than those observed in Tanzania $\left(\mathrm{r}^{2} \mathrm{AMA}-1=0.64, \mathrm{r}^{2} \mathrm{MSP}-1_{19}=0.63\right.$ both $\mathrm{p}<0.01$ ). Analysis of antibody titres found that mean titres were significantly different between plasma and saliva for all antigens and in both settings except for the saliva collect via the Oracol sampling device and fingerprick plasma (Table 1.)

When antibody levels were classified as positive or negative, prevalences detectable from plasma were significantly higher in all but one comparison (Tanzania MSP1-19 between filter paper and the saliva collected using Orasure). Using the fingerprick derived plasma antibody prevalence as the gold standard, sensitivity of the saliva test is presented in Table 2. Specificity was uniformly high (>90\%), but sensitivity varied greatly (46-76\%) though the ROC (receiver operating characteristic curve; the average of sensitivity and specificity) was consistently 0.72 or above.

\section{Discussion}

This study aimed to determine whether anti-malarial antibodies could be detected in saliva by indirect ELISA and if the detected antibodies correlated with those from plasma either collected directly or on filter papers. Results indicate good correlations between saliva and serum antibody titres for both antigens tested and weaker correlations between sero-prevalence. Given that these data are derived from two studies in different countries whose only consistency of protocol was the ELISA assay for antibody detection, the findings suggest that this innovative and non-invasive sampling method has some potential for population-based serological surveys for malaria.

Saliva, rich in serum-derived IgM and IgG, represents a convenient alternative sample collection method to serum, particularly useful when repeated blood sampling may not be possible [10]. Saliva collection has several advantages: it does not involve the usage of sharps, it is easy to collect and store and could be used to access communities with blood taboos [24]. It is also likely to 

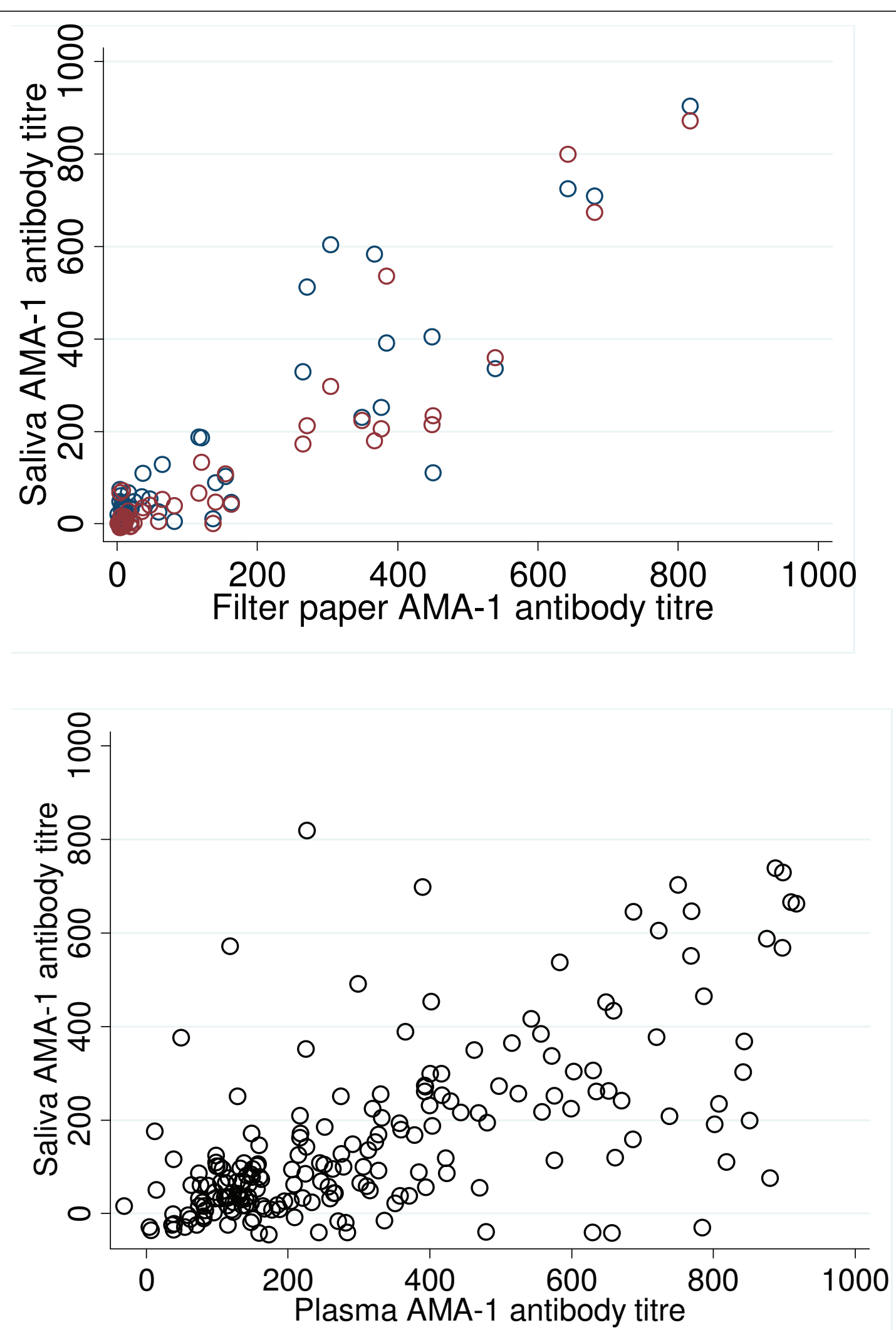

Figure 1 Scatterplots showing relationship between paired antibody titres from plasma and saliva to $P$. falciparum merozoite surface antigen AMA-1 in a)Tanzania and b) The Gambia. In plot a) open red circles represent measures by OraSure and blue circles by OraCol. 
Table 1 Comparison of antibody titres and prevalence measured in plasma and saliva against MSP-1 ${ }_{19}$ and AMA-1 $P$. falciparum merozoite surface antigens

\begin{tabular}{|c|c|c|c|c|c|}
\hline \multirow[b]{2}{*}{ Antigen } & \multicolumn{3}{|c|}{ Tanzania $(n=53)$} & \multicolumn{2}{|c|}{$\begin{array}{l}\text { The Gambia } \\
(n=200)\end{array}$} \\
\hline & Plasma & $\begin{array}{l}\text { Saliva } \\
\text { Oracol }\end{array}$ & $\begin{array}{c}\text { Saliva } \\
\text { Orasure }\end{array}$ & Plasma & Saliva \\
\hline$\frac{\mathrm{AMA}-1}{\mathrm{R}^{2}}$ & & 0.89 & 0.93 & & 0.64 \\
\hline Mean response (range) & $\begin{array}{c}138 \\
(1-817)\end{array}$ & $\begin{array}{c}148 \\
(3-902)\end{array}$ & $\begin{array}{c}108^{*} \\
(0-871)\end{array}$ & $\begin{array}{c}317 \\
(0-917)\end{array}$ & $\begin{array}{c}185^{*} \\
(45-818)\end{array}$ \\
\hline$\%$ positive & 47 & 34 & 36 & 36 & 30 \\
\hline$\frac{M S P-1_{19}}{r^{2}}$ & & 0.75 & 0.93 & & 0.63 \\
\hline Mean response (range) & $\begin{array}{c}61 \\
(0-769)\end{array}$ & $\begin{array}{c}62 \\
(0-625)\end{array}$ & $\begin{array}{c}37^{*} \\
(0-610)\end{array}$ & $\begin{array}{c}229 \\
(0-844)\end{array}$ & $\begin{array}{c}113^{*} \\
(0-612)\end{array}$ \\
\hline$\%$ positive & 28 & 26 & 15 & 30 & 20 \\
\hline
\end{tabular}

* = significant difference between means of titre response in saliva and plasma using t-test.

ND not done.

be more ethically acceptable for repeat sampling of the same individual. From a logistical standpoint, the methods used in this study could be easily transferred to other laboratories where epidemiological studies are conducted [20].

However, there are several potential limitations that need further investigation. Whilst correlations were good, the overall titres were significantly lower in saliva, as expected. This difference was most pronounced in assays conducted in The Gambia and are perhaps a result of a combination of using directly collected plasma and a non standardized saliva collection method (though collection of saliva via spitting is a simple approach). Plasma levels of hormones and antibodies are often routinely higher than those in saliva and work is required to evaluate optimal comparative dilutions [12]. The sensitivity and thus interpretation of a saliva based ELISA for detection of trypanosomiasias antibodies was found to be highly dependent on saliva dilution with a 1:20 dilution providing acceptable result and those of 1:40 not [25]. Clearly work is needed to standardise the amount and 'quality' of saliva collected. Even in Tanzania when two similar specific saliva collection methods were used, Oracol and Orasure, differences in titres were observed. These probably reflect the way each of the swabs were used as well as the storage buffer and the material they are made of and the relative recovery of saliva from the swabs $[19,26]$. Although both saliva devices yielded saliva samples suitable for the qualitative determination of malaria specific IgG antibody, these differences would require standardization for wider use. There is also significant variation in the amount of saliva produced by individuals [10]. This is compounded by the further dilution of samples with buffer a necessary addition to stabilize and preserve saliva during field collection. The identification of a standard protein against which saliva volume could be calculated would be useful. Human serum albumin is one option used in serum and alternatives for saliva need to be investigated. Similarly, defining a positive control saliva for use in future assays will be necessary.

The relationship between plasma and saliva antibody titre and prevalence differed slightly depending on the target antigen though this relates to the higher immunogenicity of AMA-1 and the antibody titre it induces. The greatest discordance between plasma and saliva titres was observed with the lowest values and this has been shown when comparing anti-malarial antibodies derived from different sources [8]. Importantly, for the antigens used in this study which have been most widely utilized in recent times as markers of exposure, [27-29], correlations were good. Indeed, combining seropositivity to both antigens in this data set increases overall sensitivity, specificity and ROC to some degree (for the Oracol device in Tanzania 70.4, 96.2 and 0.83, respectively and for The Gambia 67.2, 92.5 and 0.8, respectively). These ROC values reflect only fair accuracy but should improve with optimization and using these antigens together, ideally in a single ELISA to minimize workload, would likely provide a better measure of exposure. This study was not designed to compare results between the two study sites. However, difference in the survey methodologies used, including the different age range of the individuals recruited, will account for the some of the variability of the correlation results observed between the two sites.

This study opens the way for more extensive studies to assess the potential of human saliva in the detection of anti-malarial antibodies. Seroprevalence data from saliva has already been used to describe the immunoepidemiology of populations for meningococcal infection, tetanus and other diseases for many years $[10,11,20,22,30,31]$. Moreover, malaria parasite DNA can also be detected from saliva [15] allowing an assessment of both exposure and infection from a saliva sample. Further research in a longitudinal study would help to determine if anti-malarial saliva antibodies are influenced by food, tobacco or other diseases and could be extended to study exposure to other malaria species, such as Plasmodium vivax.

\section{Conclusions}

Ultimately, a variety of different diagnostic approaches are needed to deal with the different epidemiological and sociological scenarios in malaria. These preliminary data suggest saliva represents a potential alternative to blood for the assessment of anti-malarial antibody levels 

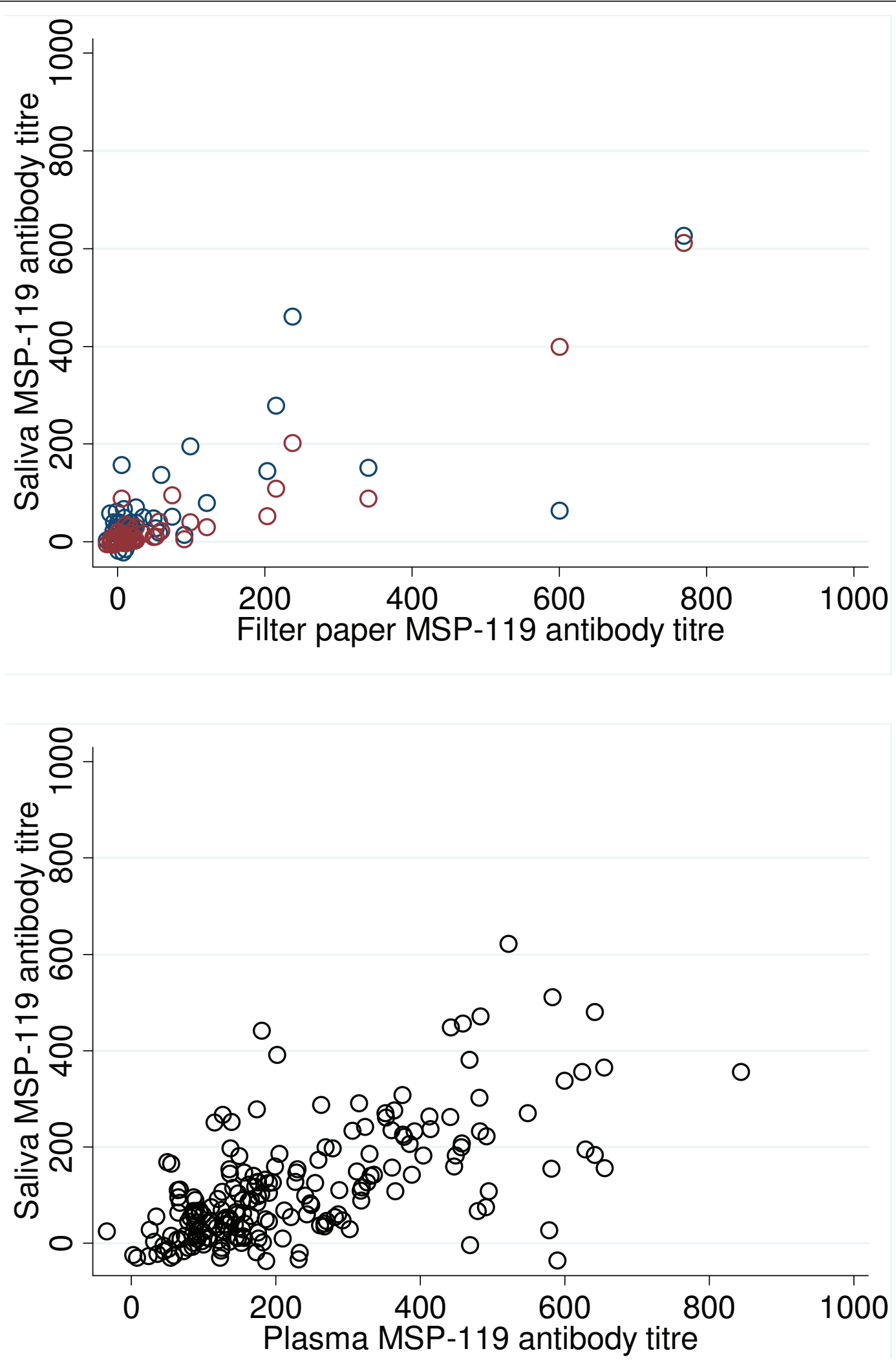

Figure 2 Scatterplots showing relationship between paired antibody titres from plasma and saliva to $P$. falciparum merozoite surface antigen MSP-1 $1_{19}$ in a) Tanzania and b) The Gambia. In plot a) open red circles represent measures by OraSure and blue circles by OraCol. 
Table 2 Sensitivity, specificity \& ROC* for saliva derived seroprevalence to $P$. falciparum merozoite surface antigens

\begin{tabular}{|c|c|c|c|}
\hline & $\begin{array}{l}\text { Sensitivity (95\% } \\
\mathrm{Cl})\end{array}$ & $\begin{array}{l}\text { Specificity }(95 \% \\
\text { Cl) }\end{array}$ & $\begin{array}{l}\text { ROC }(95 \% \\
\text { Cl) }\end{array}$ \\
\hline \multicolumn{4}{|l|}{$\underline{\text { AMA-1 }}$} \\
\hline $\begin{array}{l}\text { Tanzania } \\
\text { Oracol }\end{array}$ & 76.7 (54.9-90.6) & 100 (87.7-100) & $\begin{array}{l}0.88(0.8- \\
0.96)\end{array}$ \\
\hline $\begin{array}{l}\text { Tanzania } \\
\text { Orasure }\end{array}$ & $64(42.5-82)$ & $92.9(76.5-99.1)$ & $\begin{array}{l}0.78(0.68- \\
0.89)\end{array}$ \\
\hline The Gambia & $68(56-78.8)$ & $91.2(85-95.6)$ & $\begin{array}{l}0.80(0.74- \\
0.86)\end{array}$ \\
\hline \multicolumn{4}{|l|}{$\underline{\mathrm{MSP}^{-1} 1_{19}}$} \\
\hline Oracol & 46.7 (21.3-73.4) & 97.4 (86.2-99.9) & $\begin{array}{l}0.72(0.58- \\
0.85)\end{array}$ \\
\hline Orasure & $66.7(38.4-88.2)$ & $90.0(75.2-97.1)$ & $\begin{array}{l}0.78(0.64- \\
0.91)\end{array}$ \\
\hline The Gambia & $53(40.1-66.5)$ & $94.2(89-87.5)$ & $\begin{array}{l}0.74(0.67- \\
0.81)\end{array}$ \\
\hline
\end{tabular}

* ROC = receiver operating characteristic curve; the average of sensitivity and specificity.

Fingerprick derived plasma antibody prevalence was the gold standard for sensitivity and specificity analysis.

in population surveys. Further studies confirming and standardising the recovery of antibodies are required.

\section{Acknowledgements}

We wish to thank the participants and staff of the KTP \& MRC (UK) The Gambia. We thank Ed Remarque and Bart Faber for the provision of the AMA-1 protein, Tedson Lukindo for help in the laboratory in Moshi, Eniyou Oriero in Fajara and Patrick Corran and Jackie Cook for help and advice in London. The Gambia sampling and assays were supported by a project grant to DCN from PATH-Malaria Vaccine Initiative and Tanzania studies through a grant to from the Wellcome Trust to CD (078925) and a Grant from Bill \& Melinda Gates Foundation to SW.

\section{Author details}

${ }^{1}$ Faculty of Infectious \& Tropical Diseases, London School of Hygiene and Tropical Medicine, London, UK. ${ }^{2}$ Medical Research Council laboratories (UK), Fajara, The Gambia. ${ }^{3}$ University of Abomey-Calavi, LBBM, Cotonou, Benin. ${ }^{4}$ Wilmer Eye Institute, John Hopkins School of Medicine, Baltimore, USA.

\section{Authors' contributions}

PTE conducted the field work in Tanzania with SW, analysed the samples and wrote the first draft of the report. DCN, DJC and JS designed the study in the Gambia and JS conducted the ELISA. CD conceived the project and wrote the paper with contributions from all authors. All the authors read and approved the final manuscript.

\section{Competing interests}

The authors declare that they have no competing interests.

Received: 9 January 2011 Accepted: 29 April 2011

Published: 29 April 2011

\section{References}

1. Greenwood BM: Control to elimination: implications for malaria research. Trends Parasitol 2008, 24:449-454.

2. Drakeley CJ, Carneiro I, Reyburn H, Malima R, Lusingu JP, Cox J, Theander TG, Nkya WM, Lemnge MM, Riley EM: Altitude-dependent and -independent variations in Plasmodium falciparum prevalence in northeastern Tanzania. J Infect Dis 2005, 191:1589-1598.
3. Schellenberg D, Menendez C, Aponte J, Guinovart C, Mshinda H, Tanner M, Alonso P: The changing epidemiology of malaria in Ifakara Town, southern Tanzania. Trop Med Int Health 2004, 9:68-76.

4. Oesterholt MJ, Bousema JT, Mwerinde OK, Harris C, Lushino P, Masokoto A, Mwerinde H, Mosha FW, Drakeley CJ: Spatial and temporal variation in malaria transmission in a low endemicity area in northern Tanzania. Malar J 2006, 5:98.

5. Corran P, Coleman P, Riley E, Drakeley C: Serology: a robust indicator of malaria transmission intensity? Trends Parasitol 2007, 23:575-582.

6. Drakeley CJ, Corran PH, Coleman PG, Tongren JE, McDonald SL, Carneiro I, Malima R, Lusingu J, Manjurano A, Nkya WM, Lemnge MM, Cox J, Reyburn H, Riley EM: Estimating medium- and long-term trends in malaria transmission by using serological markers of malaria exposure. Proc Natl Acad Sci USA 2005, 102:5108-5113.

7. Webster HK, Gingrich JB, Wongsrichanalai C, Tulyayon S, Suvarnamani A, Sookto P, Permapanich B: Circumsporozoite antibody as a serologic marker of Plasmodium falciparum transmission. Am J Trop Med Hyg 1992, 47:489-497.

8. Williams G, Mweya C, Stewart L, Mtove G, Reyburn H, Cook J, Corran P, Riley E, Drakeley C: Immunophoretic rapid diagnostic tests as a source of immunoglobulins for estimating malaria sero-prevalence and transmission intensity. Malar J 2009, 8:168.

9. Razakandrainibe R, Thonier V, Ratsimbasoa A, Rakotomalala E, Ravaoarisoa E, Raherinjafy R, Andrianantenaina H, Voahanginirina O, Rahasana TE, Carod JF, Domarle O, Menard D: Epidemiological situation of malaria in Madagascar: Baseline data for monitoring the impact of malaria control programmes using serological markers. Acta Trop 2009, 111:160-167.

10. Nurkka A, MacLennan J, Jantti V, Obaro S, Greenwood B, Kayhty H: Salivary antibody response to vaccination with meningococcal $\mathrm{A} / \mathrm{C}$ polysaccharide vaccine in previously vaccinated and unvaccinated Gambian children. Vaccine 2000, 19:547-556.

11. Okiro EA, Sande C, Mutunga M, Medley GF, Cane PA, Nokes DJ: Identifying infections with respiratory syncytial virus by using specific immunoglobulin $\mathrm{G}(\mathrm{lgG})$ and $\mathrm{IgA}$ enzyme-linked immunosorbent assays with oral-fluid samples. J Clin Microbiol 2008, 46:1659-1662.

12. Hofman LF: Human saliva as a diagnostic specimen. J Nutr 2001, 131:1621S-1625,

13. Litt DJ, Samuel D, Duncan J, Harnden A, George RC, Harrison TG: Detection of anti-pertussis toxin lgG in oral fluids for use in diagnosis and surveillance of Bordetella pertussis infection in children and young adults. J Med Microbiol 2006, 55:1223-1228.

14. Piwowar-Manning EM, Tustin NB, Sikateyo P, Kamwendo D, Chipungu C, Maharaj R, Mushanyu J, Richardson BA, Hillier S, Brooks Jackson J: Validation of rapid HIV antibody tests in 5 African countries. J Int Assoc Physicians AIDS Care (Chic III) 2010, 9:170-172.

15. Nwakanma Davis C, Gomez-Escobar N, Walther M, Crozier S, Dubovsky F, Malkin E, Locke E, Conway David J: Quantitative detection of Plasmodium falciparum DNA in saliva, blood, and urine. J Infect Dis 2009, 199:1567-1574.

16. Mharakurwa S, Simoloka C, Thuma P, Shiff C, Sullivan D: PCR detection of Plasmodium falciparum in human urine and saliva samples. Malar J 2006, 5:103.

17. A-Elgayoum SME, El-Rayah EA, Giha HA: Towards a noninvasive approach to malaria diagnosis: detection of parasite DNA in body secretions and surface mucosa. J Molec Microbiol Biotechn 2010, 18:148-155.

18. Vyse AJ, Cohen BJ, Ramsay ME: A comparison of oral fluid collection devices for use in the surveillance of virus diseases in children. Public Health 2001, 115:201-207.

19. Nokes DJ, Enquselassie F, Vyse A, Nigatu W, Cutts FT, Brown DW: An evaluation of oral-fluid collection devices for the determination of rubella antibody status in a rural Ethiopian community. Trans $R$ Soc Trop Med Hyg 1998, 92:679-685.

20. Tapia MD, Pasetti MF, Cuberos L, Sow SO, Doumbia MN, Bagayogo M, Kotloff KL, Levine MM: Measurement of tetanus antitoxin in oral fluid: a tool to conduct serosurveys. Pediatr Infect Dis J 2006, 25:819-825.

21. Langel K, Engblom C, Pehrsson A, Gunnar T, Ariniemi K, Lillsunde P: Drug testing in oral fluid-evaluation of sample collection devices. J Anal Toxicol 2008, 32:393-401.

22. Sheppard C, Cohen B, Andrews N, Surridge H: Development and evaluation of an antibody capture ELISA for detection of IgG to EpsteinBarr virus in oral fluid samples. J Virol Methods 2001, 93:157-166. 
23. Duah NO, Weiss HA, Jepson A, Tetteh KK, Whittle HC, Conway DJ: Heritability of antibody isotype and subclass responses to Plasmodium falciparum antigens. PLOS ONE 2009, 4:e7381.

24. Wilson NO, Adjei AA, Anderson W, Baidoo S, Stiles JK: Detection of Plasmodium falciparum histidine-rich protein II in saliva of malaria patients. Am J Trop Med Hyg 2008, 78:733-735.

25. Lejon V, Jamonneau V, Solano P, Atchade P, Mumba D, Nkoy N Bebronne N, Kibonja T, Balharbi F, Wierckx A, Boelaert M, Büscher P: Detection of trypanosome-specific antibodies in saliva, towards noninvasive serological diagnosis of sleeping sickness. Trop Med Int Health 2006, 11:620-627.

26. Brandtzaeg P: Do salivary antibodies reliably reflect both mucosal and systemic immunity? Ann NY Acad Sci 2007, 1098:288-311.

27. Bousema JT, Youssef RM, Cook J, Cox J, Alegana VA, Amran J, Noor AM, Snow R, Drakeley C: Serologic markers for detecting malaria in areas of low endemicity, Somalia, 2008. Emerg Infect Dis 2010, 16:392-399.

28. Bousema T, Drakeley C, Gesase S, Hashim R, Magesa S, Mosha F, Otieno S, Carneiro I, Cox J, Msuya E, Kleinschmidt I, Maxwell C, Greenwood B, Riley E, Sauerwein R, Chandramohan D, Gosling R: Identification of hot spots of malaria transmission for targeted malaria control. J Infect Dis 2010, 201:1764-1774

29. Stewart L, Gosling R, Griffin J, Gesase S, Campo J, Hashim R, Masika P, Mosha J, Bousema T, Shekalaghe S, Cook J, Corran P, Ghani A, Riley EM, Drakeley C: Rapid assessment of malaria transmission using age-specific sero-conversion rates. PLOS ONE 2009, 4:e6083.

30. Wilson SD, Roberts K, Hammond K, Ayres JG, Cane PA: Estimation of incidence of respiratory syncytial virus infection in schoolchildren using salivary antibodies. J Med Virol 2000, 61:81-84.

31. Luzza F, Oderda G, Maletta M, Imeneo M, Mesuraca L, Chioboli E, Lerro P, Guandalini S, Pallone F: Salivary immunoglobulin G assay to diagnose Helicobacter pylori infection in children. J Clin Microbiol 1997, 35:3358-3360

doi:10.1186/1475-2875-10-104

Cite this article as: Estévez et al:: Human saliva as a source of antimalarial antibodies to examine population exposure to Plasmodium falciparum. Malaria Journal 2011 10:104.

\section{Submit your next manuscript to BioMed Central and take full advantage of:}

- Convenient online submission

- Thorough peer review

- No space constraints or color figure charges

- Immediate publication on acceptance

- Inclusion in PubMed, CAS, Scopus and Google Scholar

- Research which is freely available for redistribution

Submit your manuscript at www.biomedcentral.com/submit 